\title{
Mineralogical and Raman spectroscopy studies of natural olivines exposed to different planetary environments
}

\author{
I. Weber $^{\text {a,* }}$, U. Böttger ${ }^{\text {b }}$, S.G. Pavlov ${ }^{\text {b }}$, E.K. Jessberger ${ }^{a}$, H.-W. Hübers ${ }^{\text {b,c }}$ \\ a Institut für Planetologie, Wilhelm-Klemm-Str. 10, WWU Münster, 48149 Münster, Germany \\ ${ }^{\mathrm{b}}$ DLR, Institut für Planetenforschung, Rutherfordstr. 2, 12489 Berlin, Germany \\ ' Institut für Optik und Atomare Physik, Technische Universität, Straße des 17. Juni 135, 10623 Berlin, Germany
}

\section{A R T I C L E I N F O}

Article history:

Received 30 April 2014

Received in revised form 23 July 2014

Accepted 22 August 2014

Available online 28 September 2014

Keywords:

Raman spectroscopy

Olivine

Mars

Space missions

Simulated planetary conditions/

environments

\begin{abstract}
A B S T R A C T
New lander missions to bodies of our solar system are coming up and thus new techniques are desirable for the in-situ investigation of planetary surface and near surface materials. During the last decade Raman spectroscopy has been developed to become an excellent laboratory tool for fast petrological and mineralogical investigation of terrestrial and extraterrestrial rocks. Consequently, Raman spectroscopy has successfully been proposed for operation on planetary surfaces. In the joint ESA and Roscosmos mission ExoMars a Raman Laser Spectrometer (RLS) will for the first time be applied in space to identify minerals and organic compounds in Martian surface rocks and soils. The present study aims to investigate the possible response of various environmental conditions to Raman spectra in preparation for the ExoMars mission, as well as other space missions in future. For our study we selected five natural olivines with different forsterite $\left(\mathrm{Mg}_{2} \mathrm{SiO}_{4}\right)$ and fayalite $\left(\mathrm{Fe}_{2} \mathrm{SiO}_{4}\right)$ compositions. Olivine as an important rock forming mineral of the Earth upper mantle and an abundant mineral in Martian meteorites is one of the key planetary mineral. The spectra were taken in various environmental conditions that include vacuum down to $10^{-6}$ mbar, $8 \mathrm{mbar} \mathrm{CO}_{2}$ atmosphere, and temperatures ranging between room temperature and $\sim 8 \mathrm{~K}$ resembling those on Mars as well as on the Moon and on asteroids. We have found that forsterite shows only small temperature-related shifts in Raman spectra at very low temperatures indicating relatively weak changes in the lattice modes. Fayalite demonstrates, in addition to temperature dependent changes in the lattice modes found for forsterite, modification of Raman spectra at low Stokes frequencies. This is an effect in the $\mathrm{SiO}_{4}$ internal modes that most probably is caused by the high amount of iron in the mineral structure, which triggers antiferromagnetic transition at low temperatures. No influence of a $\mathrm{CO}_{2}$ atmosphere on Raman spectra for the investigated rockforming minerals has been observed at any pressure from ambient 1 bar down to a few mbar.
\end{abstract}

(c) 2014 Elsevier Ltd. All rights reserved.

\section{Introduction}

One of the fundamental aims to study minerals under different temperature and pressure conditions is to understand their formation conditions to draw conclusions about former processes on Earth as well as on other planets and/or asteroids in our solar system. In the case of space missions it is important to anticipate the expected data beforehand in order to enable proper interpretation and to optimize the instrumentation during its development.

Chemical and bond structure of minerals determined by elemental composition and atomic order in lattice can be probed by phonon spectroscopies, such as infrared absorption and

\footnotetext{
*Corresponding author. Tel.: +49 251 8339051; fax: +49 2518336301 .

E-mail address: sonderm@uni-muenster.de (I. Weber).
}

inelastic light scattering. Raman spectroscopy is well known as a powerful non-destructive technique for the investigation of mineral phases and organic matter, and does not require a special sample preparation. It allows, with detailed $\mu \mathrm{m}$-scale mappings, to catch very small particles and characterize them. A Raman instrument does not require vacuum or valves and almost no moving parts. Therefore, it appears to be an excellent analytical instrument for the in-situ exploration of planetary surface materials.

For the years 2016 and 2018 ESA will perform two missions to the Mars called ExoMars in collaboration with the Russian Federal Space Agency (Roscosmos) (Vago et al. 2012; The ExoMars Programme 2016-2018). The first ExoMars launch in 2016 is an orbiter with a trace gas analyser and, most importantly, an entry, descent and lander demonstrator module. The second launch in 2018 will contain an European rover and a Russian surface platform. This second ExoMars mission will visually and spectrally 
characterize the surface of Mars. The particular goal of the mission is, besides the investigation of the Martian rocks and soils, to search for indications of present and previous life signatures. One of the on board Pasteur Payload instruments of the ExoMars Rover is the Raman Laser Spectrometer (RLS) (Rull et al., 2011). This will be the first time that a Raman spectrometer will be flown on a planetary mission. The rover is equipped with a sampling drill capable of drilling up to $2 \mathrm{~m}$ depth. The sampled material will then be crushed into fine powder (average grain size is $0.15 \mathrm{~mm}$ ) before being analysed first by RLS and then by other instruments. To distinguish the rocks and soils from possible life forms it is necessary that all mineral phases in the drilled powder are assigned securely in advance, ideally in a RLS database.

The objective of our present study is to extend the existing database of Raman spectroscopy by adding data of a mineral kit measured especially under Martian conditions as well as other planetary conditions for future missions. A dependence of Raman shifts on environmental measurement conditions is known from literature (e.g. Kolesov and Geiger, 2004b). Here we present the investigation of five olivines measured under different environmental conditions, including Martian conditions. Olivines, are chosen because they belong to the rock forming minerals on Earth and especially forsterites are in addition a widespread mineral in Martian meteorites and thus - by inference - on the surface on Mars. Furthermore, results from other space missions (e.g. Viking, Observer, Global Surveyor, Pathfinder, Spirit, Opportunity, Express etc.) strongly suggest that olivine is present on Mars.

Olivine has an orthorhombic crystal system (space group Pbnm) with isolated silicate tetrahedra. It has $4 \mathrm{M}_{2}{ }^{2+} \mathrm{SiO}_{4}$ formula units per crystal unit cell, in where the $\mathrm{M}$ represents two different metal sites (M1 and M2), filled with $\mathrm{Mg}^{2+}$ and $\mathrm{Fe}^{2+}$ within the natural olivine solid solution Fo-Fa (Birle et al., 1968). The $\mathrm{SiO}_{4}$ tetrahedra have four internal Raman active modes $\left(\nu_{1}\right.$ : symmetric stretching, $\nu_{2}$ : symmetric bending, $\nu_{3}$ : asymmetric stretching, $\nu_{4}$ : asymmetric bending), a lattice rotation, and a lattice translation mode (Williams, 1995). In addition, within these structure the isolated $\mathrm{SiO}_{4}$ tetrahedra are linked with octahedral coordinated $\mathrm{M}^{2+}$ cations, which have two different sizes (M1: smaller, M2: larger). The smaller one, which shares only three edges with neighboring polyhedron and one with a $\mathrm{SiO}_{4}$ tetrahedra, is Raman active (e.g. Iishi, 1978; Rao et al., 1988).

The Raman active vibrational modes of olivine are between $150 \mathrm{~cm}^{-1}$ and $1100 \mathrm{~cm}^{-1}$. The most characteristic peak of olivine is a double peak (DP) between $\sim 815 \mathrm{~cm}^{-1}$ and $\sim 860 \mathrm{~cm}^{-1}$ for Fe-Mgolivines. The DP appears because the two $\mathrm{SiO}_{4}$-stretching $\left(\nu_{1}\right.$ and $\left.\nu_{3}\right)$ modes are active. In contrast to Forsterite with two clear distinguishable (spectrally resolved) peaks, the second line in DP of Fayalite is in most cases more like a shoulder peak. This lack of the second clear DP in Fayalite is an effect of the amount of $\mathrm{Mg}^{2+}$ and/or $\mathrm{Fe}^{2+}$ within the structure, which modify the vibration frequencies of $\mathrm{Si}-\mathrm{O}$ bonds (Kuebler et al. 2006). On the basis of this characteristic it is easy to separate between a magnesium rich and iron rich olivine at the first glance (Kuebler et al., 2006). All Raman active modes in olivine can be subdivided in three spectral regions (Iishi, 1978; Guyot et al., 1986; Price et al., 1986). Peaks below $400 \mathrm{~cm}^{-1}$ are attributed to the lattice modes (translational and rotational movements). Peaks between $400 \mathrm{~cm}^{-1}$ and $700 \mathrm{~cm}^{-1}$ can be connected with the internal bending of the $\mathrm{SiO}_{4}$ tetrahedron $\left(\nu_{2}\right.$ and $\left.\nu_{4}\right)$ and $\mathrm{Si}$ and $\mathrm{Mg}$ displacements. And, finally, peaks between $700 \mathrm{~cm}^{-1}$ and $1100 \mathrm{~cm}^{-1}$, including the DPs, are associated with the internal stretching of the $\mathrm{SiO}_{4}$ tetrahedron $\left(\nu_{1}\right.$ and $\nu_{3}$ ).

Raman measurements were carried out in the Stokes range from $50 \mathrm{~cm}^{-1}$ to $1150 \mathrm{~cm}^{-1}$ on polished solid samples, which are prepared with the method explained below. All spectra were obtained with the same special measurement sequence and procedure described in Section 2.3.
Investigations of olivines concerning the structure, buildings conditions, dissolution reactions, as well as its behavior under high pressure and high temperature are well known (e.g. Kolesov and Geiger, 2004a; Wang et al., 1993). Additionally, many authors interpret Raman spectra from different olivines with a variety of compositions, with different orientations, and at high pressures (e.g. Ishibashi et al., 2008; Mouri and Enami, 2008; Liu and Mernagh, 1993). Nevertheless, except of a short report by Sharma and Cooney (1990), there is a lack in measurements of Raman spectra under very low temperature and under Martian environmental conditions especially for forsterites. Kolesov and Geiger (2004b) investigated the lattice dynamic behavior of fayalite by cooling it down to $\sim 10 \mathrm{~K}$, but these authors worked with a $632.8 \mathrm{~nm}$ line of a He-Ne laser and $50 \mathrm{~mW}$ output power. In addition, Motamedi et al. (2013) measured forsterites with different compositions under Martian atmosphere, but they did it only down to $-20{ }^{\circ} \mathrm{C}$ and a $659 \mathrm{~nm}$ wavelength laser. Thus, combined Raman measurements at low temperature in Martian atmosphere and in vacuum are not known so far. In the present study we attempt to fill this gap. In the present study we investigated essentially forsterites. One fayalite was involved in the investigation kit to underline the measurements done by Kolesov and Geiger (2004b) carried out with a $632.8 \mathrm{~nm}$ laser, now with a $532 \mathrm{~nm}$ laser. In addition, fayalites are neither expected in high amounts on Mars nor in deep space regions.

\section{Samples, preparation, and methods}

\subsection{Samples}

In total we selected five olivine samples in this study. Two of them were provided by the Institute for Geosciences in Jena and three were available within the mineral collection at DLR, Berlin. Four of these olivines are forsterites, including the San Carlos olivine, and one is a fayalite. For the preparation of the ExoMars mission we investigate also other rock forming minerals. Therefore we choose an internal serial number for identification of the minerals. In the present study we analysed the olivines (Ol) with internal numbers: 21, 36, 61, 62, and 63.

\subsection{Sample preparation}

Here we present the results of the mineralogical, chemical, and Raman spectroscopic analyses of these five natural olivines. Based on the natural origin of the selected olivines, we paid special attention during preparation. The minerals were properly prepared for microscopy as well as for Raman investigations as follows:

For Raman measurements one plane parallel polished surface of an olivine grain was used whereas the exact opposite side of this parallel polished surface of the olivine grain was applied for thin section preparation, in order to do all required mineralogical (chemical composition, mineral zoning, inclusions etc.) analyses. On the basis of this preparation method (piece and counterpart) we can select one area during mineralogical investigations on the thin section for further Raman measurements on this particular area.

Because of the given dimension of the Raman vacuum chamber (Fig. 1) the maximum sample size is $10 \mathrm{~mm} \times 10 \mathrm{~mm} \times 5 \mathrm{~mm}$. Thin sections have the same square size but with a thickness of $30 \mu \mathrm{m}$ instead of $5 \mathrm{~mm}$. Since the original geometry of the samples was kept, no surface has a specific crystallographic orientation in a particular main crystallographic axis.

\subsection{Methods}

First overview images of the samples were obtained with the KEYENCE Digital Microscope VHX-500F. For the initial characterization 
a

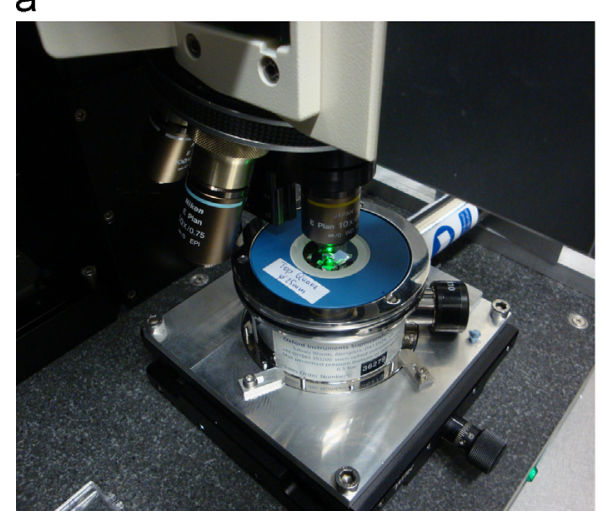

b

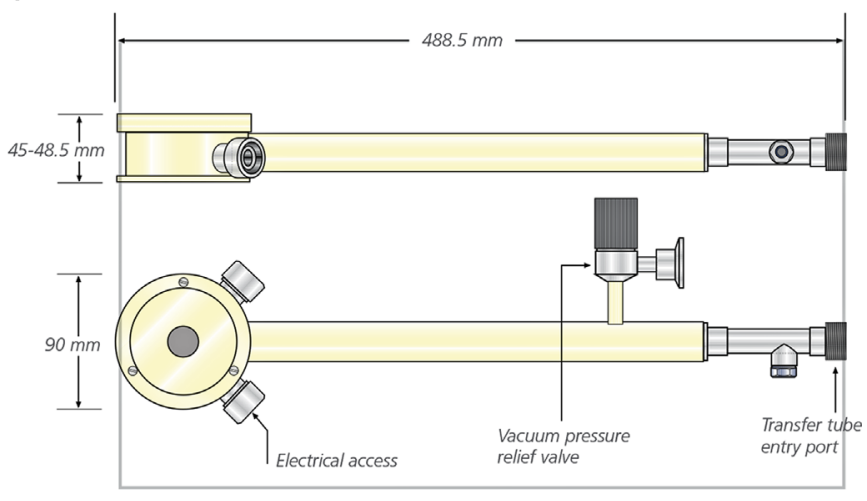

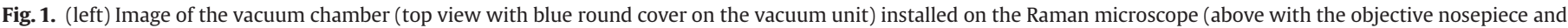

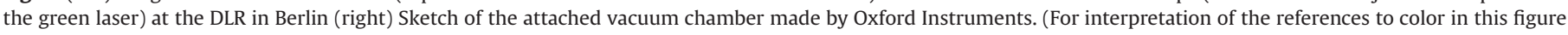
legend, the reader is referred to the web version of this article.)

Table 1

Size and origin of the investigated olivines.

\begin{tabular}{|c|c|c|c|}
\hline No. & Size (appr.)/habitus & Locality (origin) & Provided by \\
\hline 21 & $7 \mathrm{~mm} \times 7 \mathrm{~mm} /$ single crystal & Dreiser Weiher, Germany & Jena \\
\hline 36 & $9 \mathrm{~mm} \times 3 \mathrm{~mm} /$ single crystal & Feldstein, TH, Germany & Jena \\
\hline 61 & $10 \mathrm{~mm} \times 10 \mathrm{~mm} /$ single crystal & San Carlos Reservation, Arizona, USA & Berlin \\
\hline 62 & $11 \mathrm{~mm} \times 10 \mathrm{~mm} /$ multi-crystal (Fig. 2) & Dreiser Weiher, Germany & Berlin \\
\hline 63 & $10 \mathrm{~mm} \times 5 \mathrm{~mm} /$ single cracked crystal & Billiton, Sumatra, Indonesia & Berlin \\
\hline
\end{tabular}

of the olivines we used light optical microscopy equipped with a polarization unit. Subsequently we produced overview and proper images of all minerals with a JEOL JSM-6610LV scanning electron microscope (SEM). In addition, element mappings and first analyses were made on the coated thin sections. All SEM measurements were carried out at an accelerating voltage of $20 \mathrm{kV}$. Light microscopy, backscattered electron images (BSE) as well as elemental mapping gives information about possible inclusions and zonings, and the general homogeneity or heterogeneity of the samples. Knowing these aspects is important for subsequent Raman investigations to avoid measurements on an inclusion or an inhomogeneous sample position.

Detailed quantitative analyses of the olivines were made with a JEOL JXA-8900 Superprobe electron probe micro analyser (EPMA) equipped with four wavelength dispersive spectrometers and operating at an excitation voltage of $15 \mathrm{kV}$ and a beam current of $15 \mathrm{nA}$. Corrections for matrix effect were made using the $\Phi \rho(z)$ procedure of Armstrong (1991). Natural and synthetic standards of well-known compositions were used as standards.

All Raman measurements were performed with a confocal Raman microscope Witec alpha300 R system. The laser excitation wavelength is $532 \mathrm{~nm}$ and the spectral resolution is about $4 \mathrm{~cm}^{-1}$ (the distance between 2 pixels). A Nikon $10 \times$ objective was used with a given spot size on the sample in focus of about $1.5 \mu \mathrm{m}$. To compare our data with those of the RLS instrument on ExoMars a laser power of $7 \mathrm{~mW}$, which produce comparable power density on the sample, was chosen. Every spectrum is the result of a time series of 50 single spectra with $10 \mathrm{~s}$ acquisition time for each single spectrum. For each measurement series the Rayleigh line of the scattered laser emission was adjusted to a zero position on the relative wavenumber unit scale. Furthermore an edge filter was used. For data interpretation a Gaussian fit was used to find the exact position of the maximum of each peak.

For the investigations each sample was fixed in the cryostat and the sequence of measurements in the cryostat was as follows: at room temperature under air at ambient pressure (1 bar), further referred as laboratory conditions;

in vacuum ( $<10^{-4} \mathrm{mbar}$ ) from $300 \mathrm{~K}$ and $200 \mathrm{~K}$ and, to verify low-temperature behavior, $\sim 8 \mathrm{~K}$ (vacuum conditions);

in $\mathrm{CO}_{2}$-atmosphere of $6-8 \mathrm{mbar}$ at $300 \mathrm{~K}$ and $200 \mathrm{~K}$ (Mars-like conditions); and

finally, laboratory conditions again to check for irreversible changes of the minerals that might have led to changes of the Raman spectra.

For all cooling experiments the High Stability Microscopy $4 \mathrm{~K}$ Cryostat - MicrostatHiRes2 from Oxford Instruments with an automatic temperature control was used (Fig. 1). The samples were fixed on a small holder with their flat side to the cold finger in a low vibration cryostat with an automatic control of temperature. This holder allows samples with a maximum diameter of $20 \mathrm{~mm}$ and a maximum thickness of $5 \mathrm{~mm}$. The cooling effect was achieved with liquid helium that flew along a transfer tube to a heat exchanger. The cooling accuracy at the lowest value of $\sim 8 \mathrm{~K}$ is better than $1 \mathrm{~K}$. At higher temperatures it is even more precise. Nevertheless, in each case, additional few minutes were waited before taking a measurement after approaching required temperature by a cold finger in order to reach thermal equilibrium within the sample.

\section{Results}

The overall size, habitus, and origin of the olivines are given in Table 1. All mineralogical results are given in the following section and as an example in Fig. 2. Beneath detailed qualitative investigations the results of quantitative chemical analyses obtained with EPMA are listed in Table 2, which also includes the resulting forsterite (Fo) and fayalite (Fa) contents. After these initial investigations Raman measurements on defined areas on the olivines 


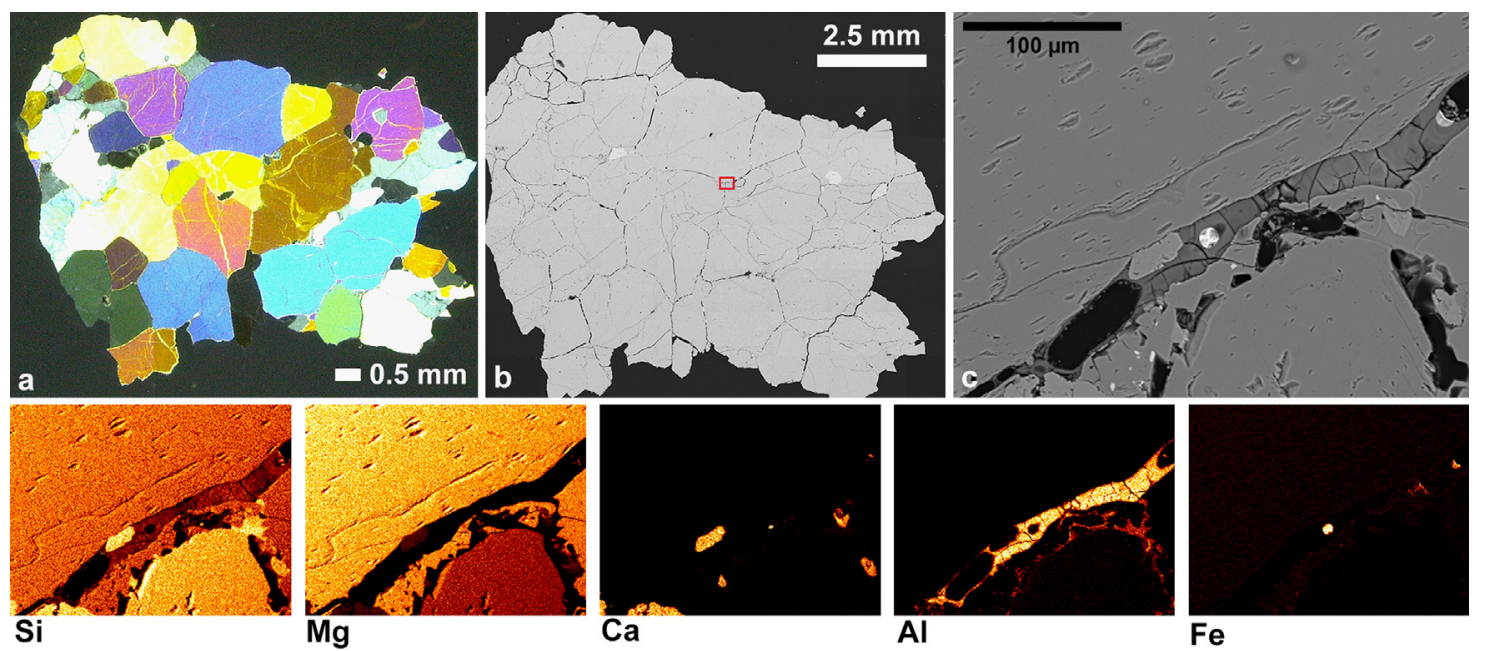

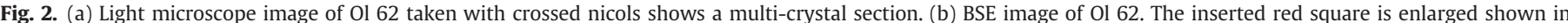

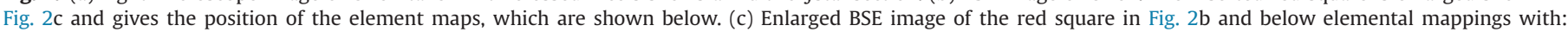
pyroxene (high $\mathrm{Si}, \mathrm{Ca}$ ), glassy material (high $\mathrm{Al}$ ), and an Fe-blebb (high $\mathrm{Fe}$ ) in addition to olivine (high $\mathrm{Mg}$ ).

Table 2

EPMA analyses in wt\% of the five olivines and Forsterite (Fo) and Fayalite (Fa) content in mole\% (n.d.=not detected).

\begin{tabular}{lccccl}
\hline & 21 & 36 & 61 & 62 & 63 \\
\hline $\mathrm{SiO}_{2}$ & 41.0 & 40.8 & 40.2 & 40.2 & 29.6 \\
$\mathrm{MgO}$ & 49.2 & 49.4 & 49.2 & 49.6 & 0.59 \\
$\mathrm{FeO}$ & 9.2 & 8.9 & 9.5 & 8.4 & 66.4 \\
$\mathrm{MnO}$ & 0.16 & 0.15 & 0.13 & 0.13 & 4.0 \\
$\mathrm{NiO}$ & 0.39 & 0.39 & 0.39 & 0.37 & n.d. \\
$\mathrm{Total}$ & 99.95 & 99.64 & 99.42 & 98.70 & 100.59 \\
$\mathrm{Fo}$ & 90.5 & 90.8 & 90.2 & 91.3 & 1.5 \\
$\mathrm{Fa}$ & 9.5 & 9.2 & 9.8 & 8.7 & 98.5 \\
\hline
\end{tabular}

were performed. The Raman results are presented also in next section and Figs. 3-11.

\subsection{Mineralogical results}

Olivine 21: This sample is a $7 \times 7 \mathrm{~mm}^{2}$ homogeneously forsteritic crystal (Fo90.5, Table 2) sample without zoning. Only one small inclusion $(\sim 200 \mu \mathrm{m} \times \sim 10 \mu \mathrm{m})$ contains $\mathrm{FeO}$ and plagioclase. Also the elemental mappings demonstrate the homogeneity of this section, only $\mathrm{Si}, \mathrm{Mg}$, Fe, and $\mathrm{O}$ were analysed by Energy Dispersive Spectroscopy (EDS).

Olivine 36: This $9 \times 3 \mathrm{~mm}^{2}$ sample is also a homogeneous forsterite crystal (Fo90.8, Table 2) without zoning. Similar to Ol 21, it has one minor inclusion $(150 \mu \mathrm{m} \times 10 \mu \mathrm{m})$. Further detailed investigations and elemental mappings on this inclusion prove the occurrence of iron oxide, plagioclase, and pyroxene. Elemental mappings result in a homogeneous sample except of the small inclusion.

Inasmuch as the elemental distribution of $\mathrm{Ol} 36$ and the ensuing $\mathrm{Ol} 61$ are extremely homogeneous like $\mathrm{Ol} 21$, they are not shown.

Olivine 61: The investigated section from the San Carlos olivine is $10 \times 10 \mathrm{~mm}^{2}$ in size. It is a homogeneous crystal. Different colors in crossed nicols are a hint towards slight differences in orientation, possibly due to minor mechanical stress. In addition, some small crack fillings in a small up to $15 \mu \mathrm{m}$ width crack are detected. As usual for a San Carlos olivine (Jarosewich et al., 1980) the overall Fo content is 90.2 (Table 2) with a small amount of Ni. Elemental mapping gives a hint of the unity of this section, only $\mathrm{Si}, \mathrm{Mg}, \mathrm{Fe}, \mathrm{Ni}$, and $O$ could be analysed by EDS.
Olivine 62: Although olivine 62 comes from the same reservoir as $\mathrm{Ol} 21, \mathrm{Ol} 62$ is a multi-crystal section (Fig. 2a,b) with $11 \times 10 \mathrm{~mm}^{2}$ in size, containing single crystals of forsterite and also low-Ca pyroxene. As shown in the elemental mappings (Fig. 2c) glassy material, containing $\mathrm{Al}, \mathrm{Ti}$, and $\mathrm{O}$, as well as an Fe-bleb and a high-Ca pyroxene fill the cracks separating olivine from pyroxene. Olivine could be distinguished from pyroxene by a lower Si content within the maps. For quantitative analyses a pure single crystal was selected. Albeit $\mathrm{Ol} 62$ has the same origin as $\mathrm{Ol}$ 21 it has somewhat different Fo content of 91.3 (Table 2).

Olivine 63: This $10 \times 5 \mathrm{~mm}^{2}$ section contains fayalite as a multicrystal cracked by large veins of a pyroxene-like material and $\mathrm{FeO}$. Slightly different orientations within the fayalite are recognizable due to different colors with crossed nicols. Fayalite (Fa98.4, Table 2) has a high Mn content of $0.11 \mathrm{~mol} \%$. Here most possible $\mathrm{Mg}$ is exchanged by Mn. The elemental mapping gives an overview of the meaningfully measurable elements ( $\mathrm{Si}, \mathrm{Fe}, \mathrm{O}, \mathrm{Mn})$ in this section.

\subsection{Raman spectroscopy results}

Olivine 21, 36, 61, 62: The spectra of these olivines measured in vacuum at room temperature (RT) resemble those of known forsterite spectra where the main peaks are located at around $\sim 824 \mathrm{~cm}^{-1}$ and around $\sim 859 \mathrm{~cm}^{-1}$. The positions of the main peaks of all forsterites (Table 3 ) are in the range of the forsterite contents analysed by EPMA compared with investigations made by Kuebler et al. (2006).

Furthermore, a relationship between Raman spectral pattern of the main peaks and crystallographic orientation of forsterites by using the relative intensities of DP lines are known. Ishibashi et al. (2008) investigate Raman spectra of a Fo $\mathrm{Fo}_{89}$ olivine in the range of $700-1050 \mathrm{~cm}^{-1}$, which includes the DP the most characteristic feature for olivines Raman spectra. Ishibashi et al. (2008) found that the relatively height of one of the DPs can be associated with the crystallographic direction of the investigated olivine. According to their findings and our measurements (Fig. 3) the orientation of the investigated olivine areas are roughly estimated: Ol 21 is orientated near the [100] axis, Ol 36 near to the [010] axis, and Ol 61 and 62 near to the [001] axis. Lower Stoke lines show, if any, very slight effects on the change in orientation and cannot be used for identification.

Moreover, Raman spectra measured at different temperatures show at a first glance no considerable temperature dependent 


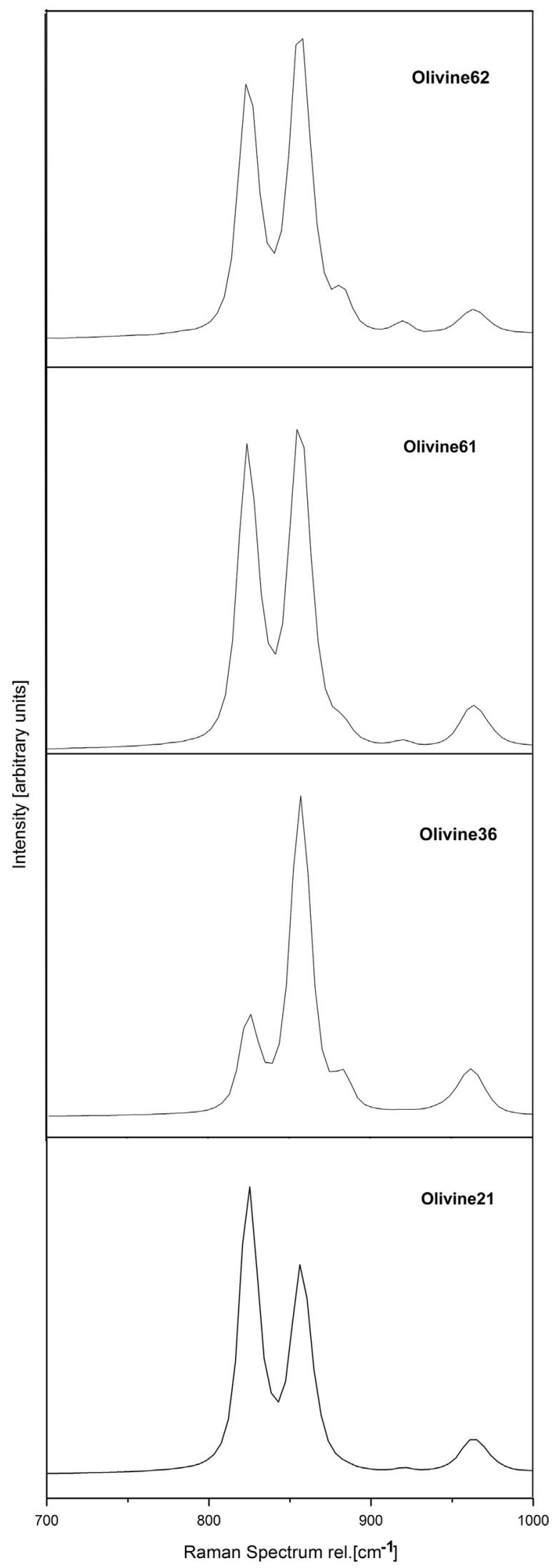

Fig. 3. Raman spectra taken at RT of the main peaks of the four investigated forsterites. Note different relations of line intensities of the DP to each other indicating on crystal orientation. Olivine 21 near [100], olivine 36 near [010], olivine 61 and 62 near [001].

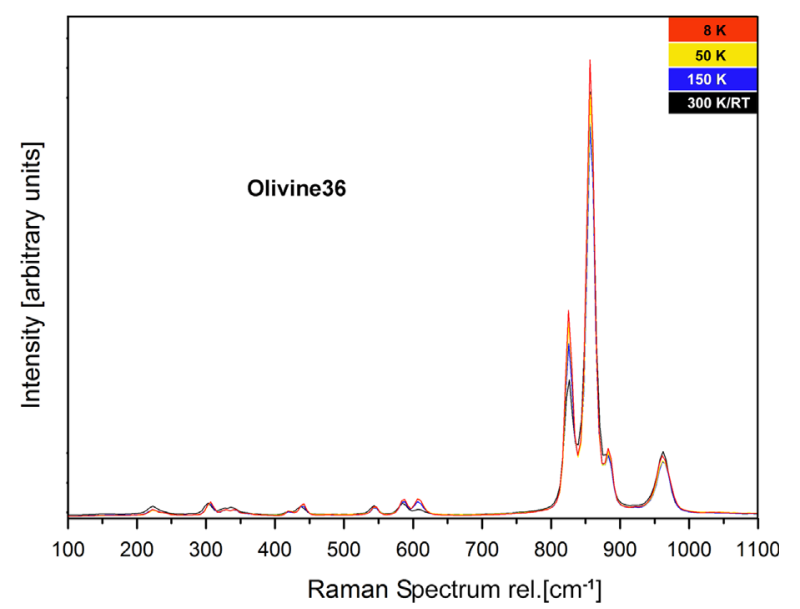

Fig. 4. Raman spectra of olivine 36 at four different temperatures from $100 \mathrm{~cm}^{-1}$ to $1100 \mathrm{~cm}^{-1}$.

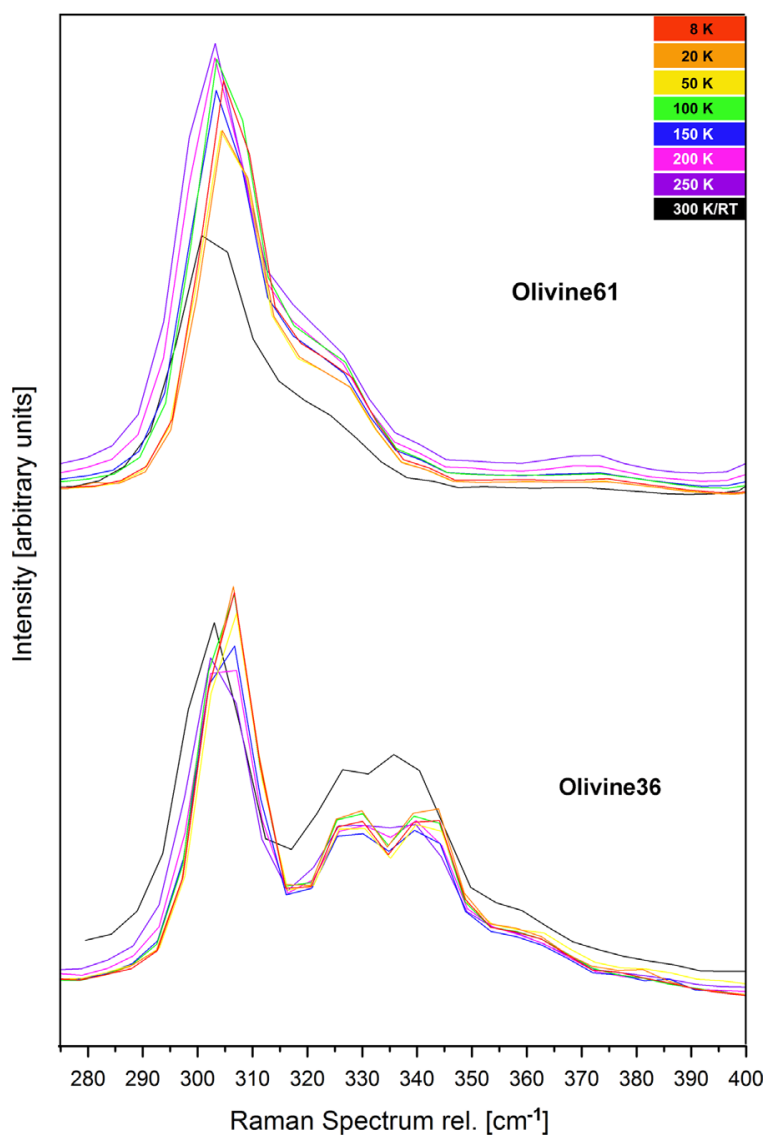

Fig. 5. Zoomed Raman spectra of olivine 36 (bottom) and olivine 61 (top) from $270 \mathrm{~cm}^{-1}$ to $400 \mathrm{~cm}^{-1}$ show shifts in the Raman line positions at different temperatures. (For all following figures with Raman spectra measured at different temperatures a fixed color scale is used, which is: black =room temperature (RT), purple $=250 \mathrm{~K}, \quad$ pink $=200 \mathrm{~K}, \quad$ blue $=150 \mathrm{~K}, \quad$ green $=100 \mathrm{~K}, \quad$ yellow $=50 \mathrm{~K}$, orange $=20 \mathrm{~K}$, red $=8 \mathrm{~K}$.) (For interpretation of the references to color in this figure legend, the reader is referred to the web version of this article.)

shifts. Fig. 4 shows as an example four Raman spectra of $\mathrm{Ol} 36$ measured at $8 \mathrm{~K}, 50 \mathrm{~K}, 150 \mathrm{~K}$, and RT. All visible Raman active modes are known from other forsterites (Chopelas, 1991). However, if we examine each single Raman peak in more detail it turned out that all four forsterites exhibit shifts of the peaks at low wavenumbers, $<600 \mathrm{~cm}^{-1}$ (Figs. 5-7). The observable changes of 


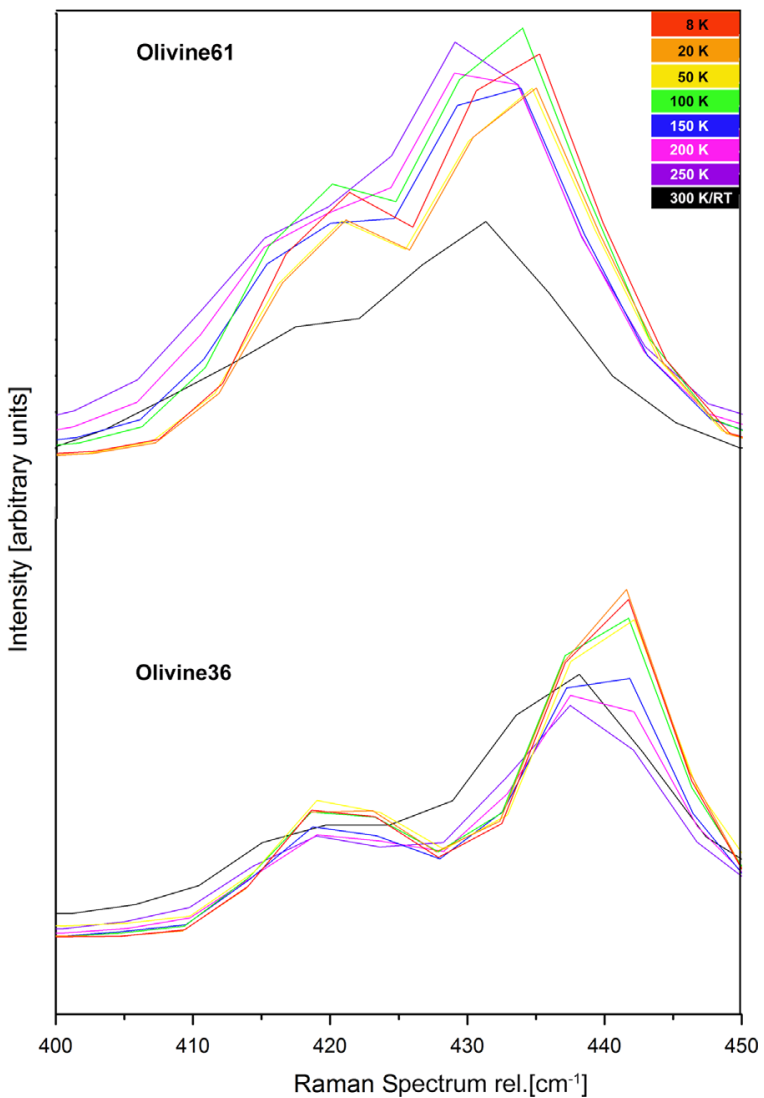

Fig. 6. Zoomed Raman spectra of olivine 36 (bottom) and olivine 61 (top) both from $400 \mathrm{~cm}^{-1}$ to $450 \mathrm{~cm}^{-1}$ show shifts in the Raman line positions at different temperatures.

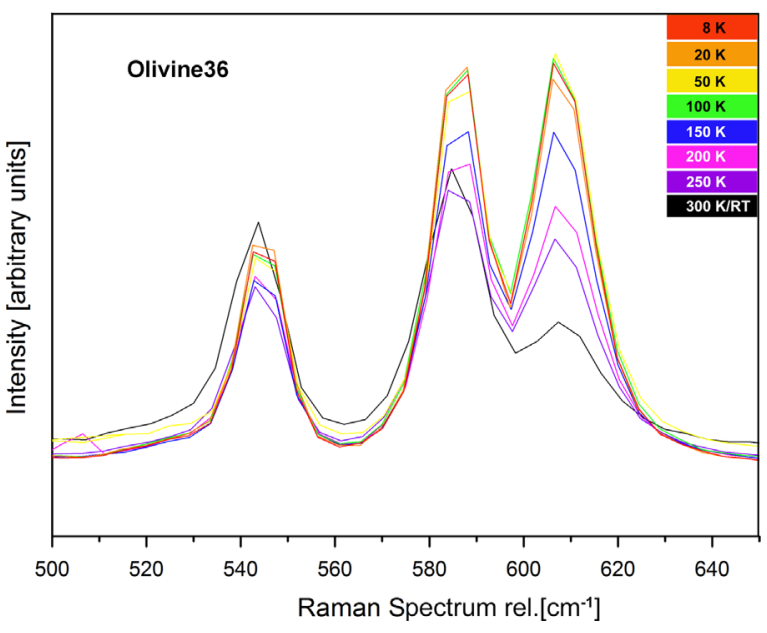

Fig. 7. Zoomed Raman spectra of olivine 36 from $500 \mathrm{~cm}^{-1}$ to $650 \mathrm{~cm}^{-1}$ show shifts in the line positions at different temperatures.

the peak positions start in all cases at $200 \mathrm{~K}$ (pink line) or even below (blue line). Shifts in the Raman spectra of display are at the peak/DP $(\mathrm{DP}=$ double peak $)$ around $300 \mathrm{~cm}^{-1} / 325 \mathrm{~cm}^{-1}$ as well as at the peak/DP around $420 \mathrm{~cm}^{-1} / 435 \mathrm{~cm}^{-1}$ (Figs. 5 and 6). In addition, a shift at the $540 \mathrm{~cm}^{-1}$ peak is visible and the building of a DP starting at $580 \mathrm{~cm}^{-1}$ must be taken into account (Fig. 7). And, furthermore, although the peak intensities are very low, Ol 61 and Ol 62 show larger shifts at $\sim 237 \mathrm{~cm}^{-1}$, and 0136 at $\sim 339 \mathrm{~cm}^{-1}$.

During our investigations, only shifts are considered when the difference values between $T_{\max }$ and $T_{\min }$ from RT (room

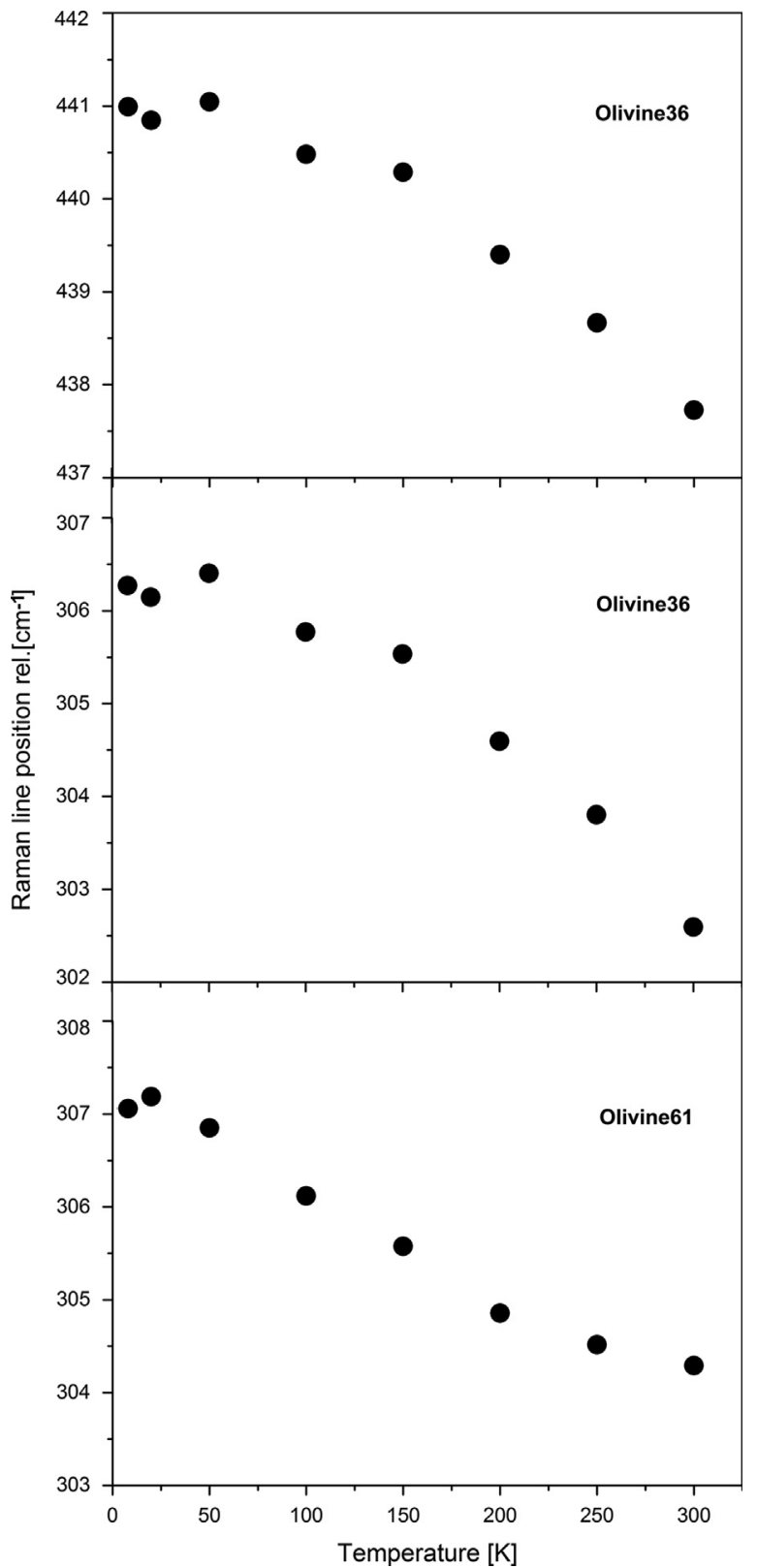

Fig. 8. Diagrams of the temperature ( $x$-axis) vs. gauss fitted peak positions of the Raman line positions ( $y$-axis) of olivine 36 (top, middle), and olivine 61 (bottom).

temperature) down to $\sim 8 \mathrm{~K}$ shows a remarkable gradient. Shifts below $2 \mathrm{~cm}^{-1} / 290 \mathrm{~K}$ are not taken into account, because of the given spectral resolution.

In addition to the spectra and as an example for the strongest shifts the relative wavenumber of the Raman line positions are plotted against the temperature for $\mathrm{Ol} 36$ and $\mathrm{Ol} 61$ in Fig. 8. In this figure, the shifts of the Raman line positions are directly visible to the beginning of the temperature decrease.

Olivine 63: The spectrum of fayalite measured at RT resembles a known fayalite spectra in which the main peak is located at $\sim 818 \mathrm{~cm}^{-1}$ with a shoulder peak at $\sim 832 \mathrm{~cm}^{-1}$ (Fig. 9). The position of this main peak confirms the presence of fayalite (e.g. Robie et al., 1982), which was also analysed with EPMA. In contrast to the forsterites, fayalite displays larger than $2 \mathrm{~cm}^{-1}$ shifts in nine Raman line positions (Fig. 10a-d). Additionally, it is observable in Fig. 10 that shifts become more visible within the spectra below $150 \mathrm{~K}$. Compared to forsterite with rather small values all measured shifts in fayalite are larger than $3 \mathrm{~cm}^{-1} / 290 \mathrm{~K}$, except of two 


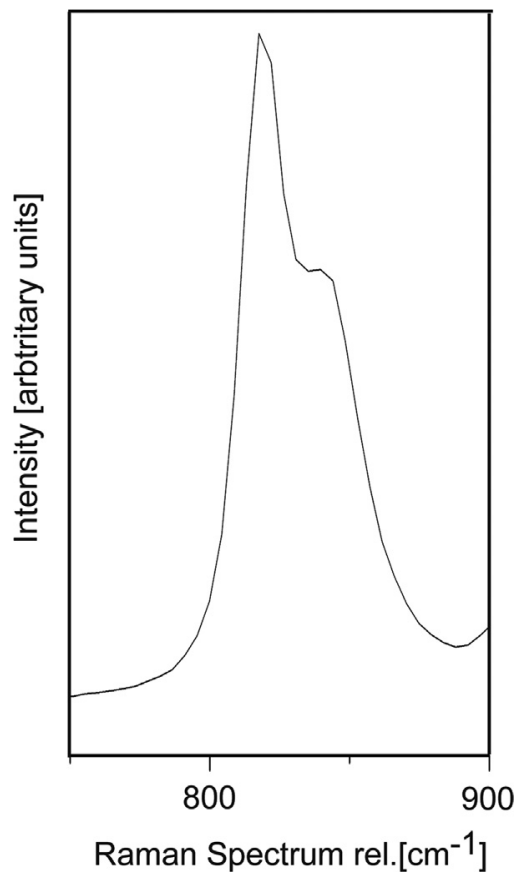

Fig. 9. Raman spectra of the main peak including the shoulder peak of olivine 63 at room temperature (RT). shifts at the wavenumbers at $\sim 155 \mathrm{~cm}^{-1}$ and at the main peak at $\sim 818 \mathrm{~cm}^{-1}$. The other peaks are located at RT at the wavenumbers $\sim 198 \mathrm{~cm}^{-1}, \sim 242 \mathrm{~cm}^{-1}, \sim 313 \mathrm{~cm}^{-1}, \sim 385 \mathrm{~cm}^{-1}, \sim 568 \mathrm{~cm}^{-1}$, $\sim 665 \mathrm{~cm}^{-1}$, and at $\sim 943 \mathrm{~cm}^{-1}$ (Fig. 10a-d). In particular at around $\sim 385 \mathrm{~cm}^{-1}$ one unresolved peak is visible at RT. Starting around $\sim 150 \mathrm{~K}$ it resolves and a second peak starts to grow. The formerly single peak turned out as a double peak at $\sim 8 \mathrm{~K}$ (Fig. 10b). Also remarkably beneath the peak shift is that the peak amplitude growth of the $556 \mathrm{~cm}^{-1}, \sim 669 \mathrm{~cm}^{-1}$, and at $\sim 943 \mathrm{~cm}^{-1}$ peaks (Fig. 10c,d) with temperature decreasing. At around $100 \mathrm{~K}$ these peaks grow notable.

As for forsterites also in the case of fayalite only shifts are considered when the difference values between $T_{\max }$ and $T_{\min }$ from RT (room temperature) down to $\sim 8 \mathrm{~K}$ shows a significant gradient. Just as for forsterite shifts under $2 \mathrm{~cm}^{-1} / 290 \mathrm{~K}$ are not taken into account.

And, in addition to this visible peak increasing, the highest temperature dependent shifts of the relative wavenumber of the Raman line position against the temperature are plotted in Fig. 11. The dependence of the Raman line positions in relation to the temperature is visible directly at the start of lowering the temperature.

To define the crystal direction the measured peaks of fayalite are compared with those measured by Chopelas (1991). As a result it can be determined that we look here near to the (001) plane.

After all cooling experiments each olivine measured again by Raman spectroscopy to investigate probable irreversible damage

b
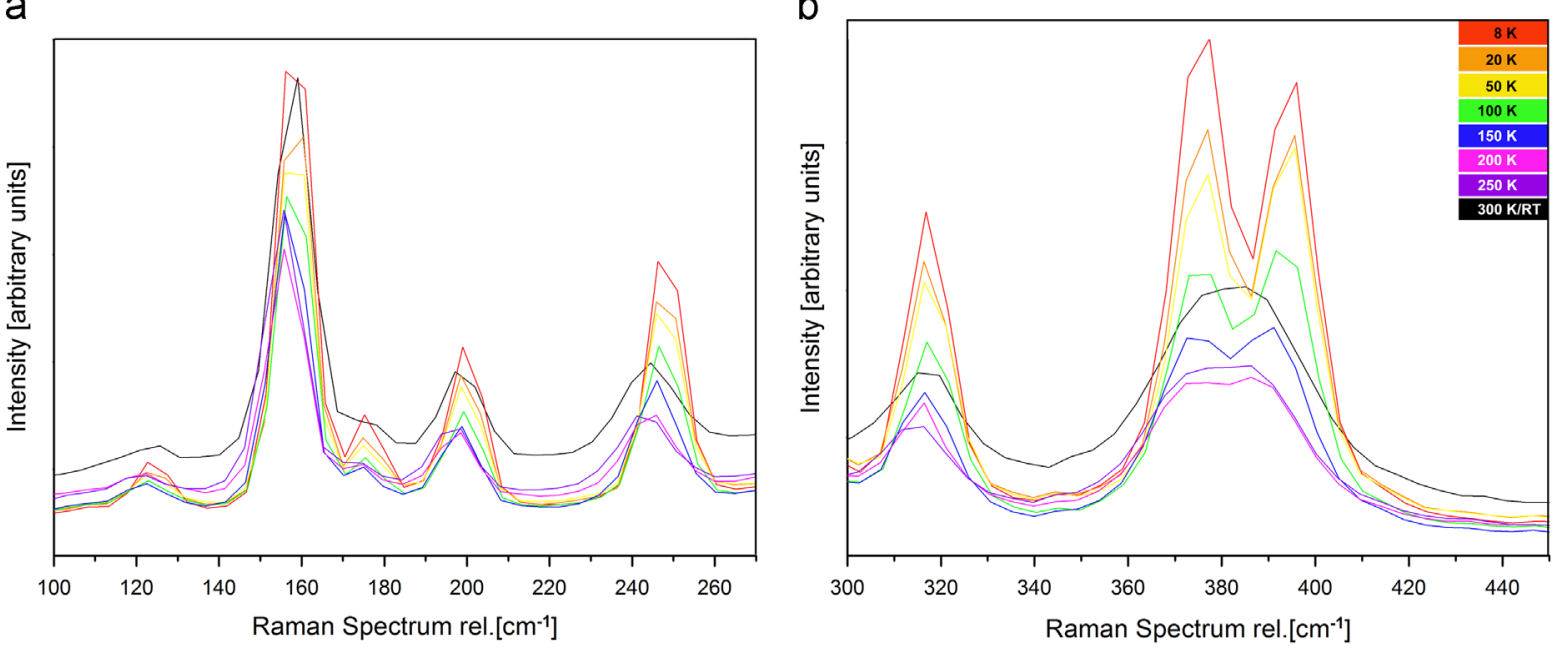

d

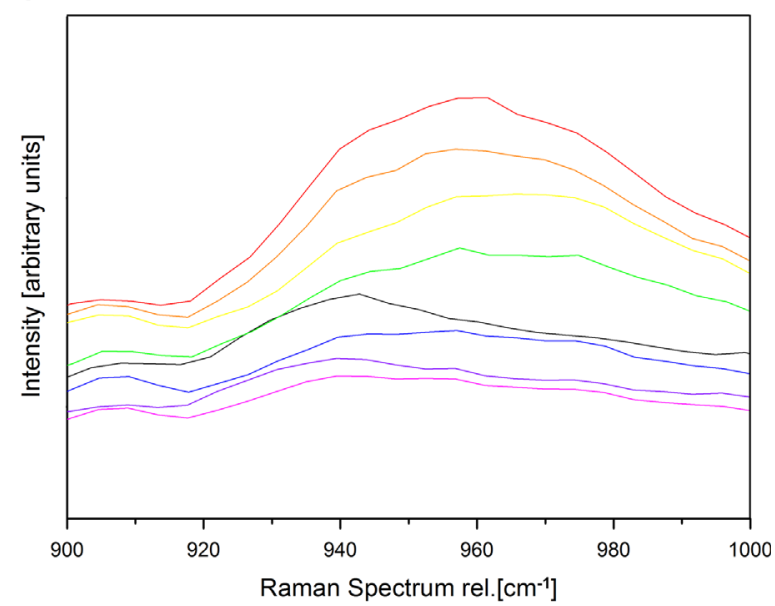

Fig. 10. Zoomed Raman spectra of olivine 63 for different ranges of Raman line position at different temperatures. 


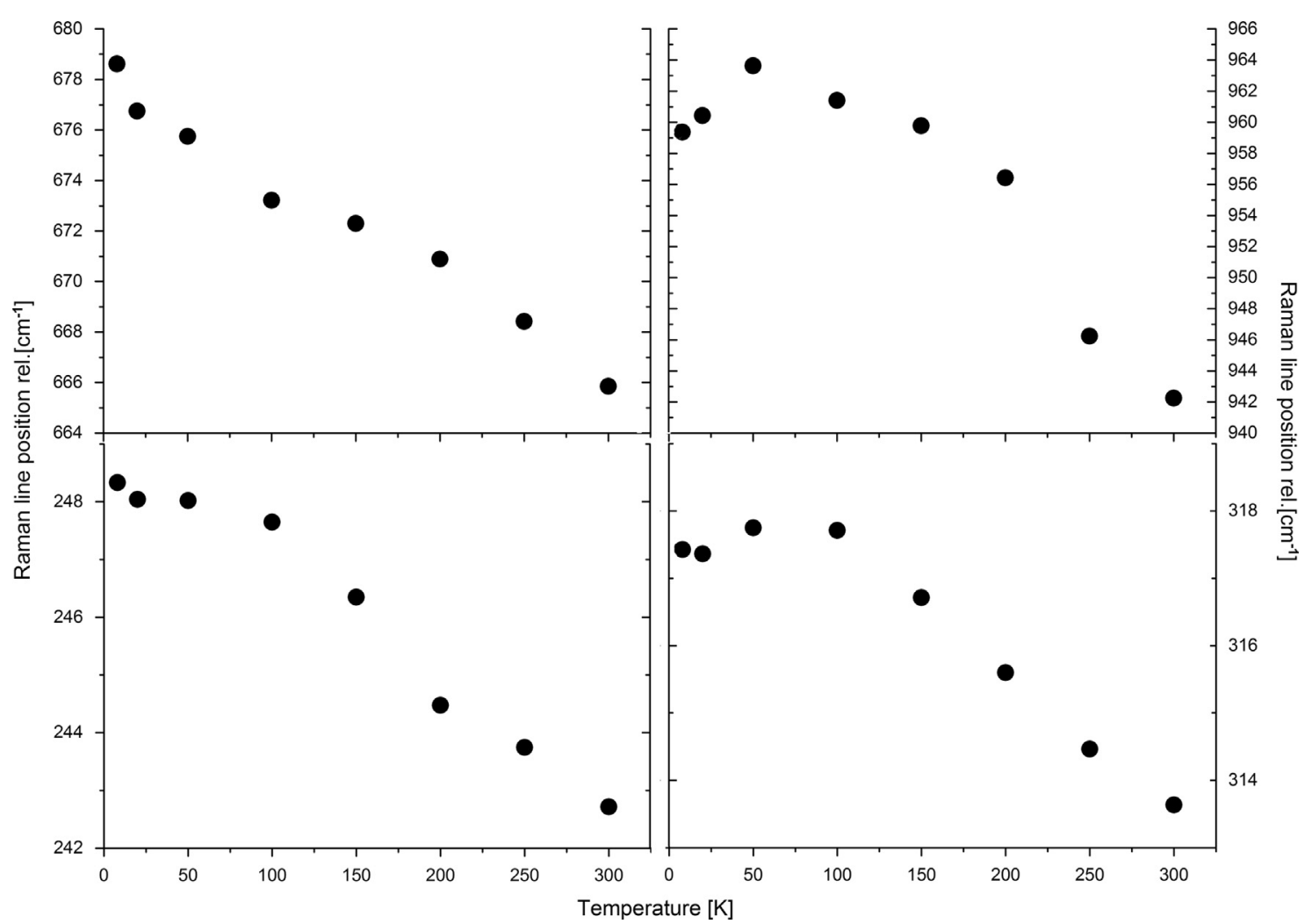

Fig. 11. Diagrams of the temperature ( $x$-axis) vs. gauss fitted peak positions of the Raman line positions ( $y$-axis) of olivine 63.

Table 3

Positions of the main double peaks in $\mathrm{cm}^{-1}$ of $\mathrm{Ol} 21, \mathrm{Ol} 36, \mathrm{Ol} 61, \mathrm{Ol} 62$, and $\mathrm{Ol} 63$.

\begin{tabular}{lllll}
\hline Ol 21 & Ol 36 & Ol 61 & Ol 62 & Ol 63 \\
\hline 825 & 824 & 824 & 824 & 818 \\
859 & 858 & 858 & 858 & 832 (shoulder peak) \\
\hline
\end{tabular}

in the minerals. But, no irreversible changes of olivine due to the cooling-reheating cycle are measured.

In this work we investigated, in addition to the temperature dependence, also the behavior of the olivines under different environmental conditions. During our study we have found no variations of the Raman spectra by changing the pressure or the composition of atmosphere (air/ $\left./ \mathrm{CO}_{2}\right)$.

\section{Discussion}

The Raman spectroscopy results in combination with proper analytic methods gave fundamental results for upcoming space missions to Mars or to any other planet and/or asteroid. All observed temperature dependent Raman active modes change with decreasing temperature to higher values of Raman line position with a trend of approaching a fixed frequency at below $\sim 50-100 \mathrm{~K}$. Our observations allow the identification of shifts at several Raman active modes depending on the crystallography and composition. The absolute shift values do not exceed $\sim 1 \mathrm{~cm}^{-1}$ per investigated cooling step for Fo and $\sim 2.5 \mathrm{~cm}^{-1}$ per investigated cooling step for Fa, which is in the detection limit of a Raman spectrometer. Therefore we conclude that in case of a Mars mission, with the lowest temperature of about $180 \mathrm{~K}$ on Mars, Raman spectra will be neither affected by the local temperature nor by the different atmospheric conditions. In the event of another mission e.g. to an asteroid where temperatures are much lower one should expect shifts of Raman peak positions from those measured at room temperatures.

In detail:

The temperature dependent shifts, found in Raman frequency lines of forsterites at $\sim 300 \mathrm{~cm}^{-1}$ and $\sim 320 \mathrm{~cm}^{-1}$, are independent from composition and orientation and can be assigned to the M2 translational and the $\mathrm{SiO}_{4}$-libration modes (McMillan, 1985; Chopelas, 1991). These two modes belong to external lattice modes, originated from $\mathrm{Mg}$ and $\mathrm{Si}$ displacements in the lattice (Price et al., 1986). That is, although we do not know how the thermodynamic interaction behaves within the crystal, our study shows once more the change in the atomic vibrations of the olivine at lower temperatures. In the frequency range $400 \mathrm{~cm}^{-1}$ up to $650 \mathrm{~cm}^{-1}$ the $\nu_{2}$ and $\nu_{4} \mathrm{SiO}_{4}$ internal bending (symmetric: $\nu_{2}$ and asymmetric: $\nu_{4}$ ) modes contribute additionally as a mixture of lattice and internal mode to the Raman spectra (Paques-Ledent and Tarte, 1973; Iishi, 1978; Chopelas, 1991). In this work shifts up to $3 \mathrm{~cm}^{-1}$ for Raman lines at around $\sim 420 \mathrm{~cm}^{-1}$ and $\sim 430 \mathrm{~cm}^{-1}$ are observed also for all four forsterites. After Iishi (1978), Price et al. (1986), and Chopelas (1991) these modes are caused by a mixture of $\nu_{2}$ plus a $\mathrm{SiO}_{4}$ lattice libration or only by $\nu_{2}$. Significant shifts in lines at higher frequencies, where $\nu_{1}$ and $\nu_{3} \mathrm{SiO}_{4}$ internal stretching are responsible for Raman activity, are not observed. Two different peak shifts in the investigated olivines are only

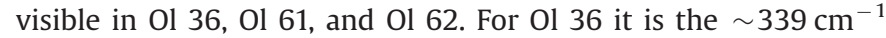
peak frequency that fits to another M2 translation lattice mode (Chopelas, 1991). For Ol 61 and 62 it is the $237 \mathrm{~cm}^{-1}$ peak frequency, which belongs also to a lattice mode (Guyot et al., 1986). These additional peak shifts are likewise correlated to the orientation of the olivines, because $\mathrm{Ol} 61$ and $\mathrm{Ol} 62$ have the same orientation in [001] whereas Ol 36 is orientated in [010]. In contrast, Ol 21, which is orientated in [010] shows neither the $237 \mathrm{~cm}^{-1}$ shift nor the $339 \mathrm{~cm}^{-1}$ shift.

Our results on the Raman study of forsterites confirm the temperature dependence of low frequency vibrations in the 
investigated forsterites. Most of the shifts are related to external lattice modes (translational and rotational movements) for wavelength below $400 \mathrm{~cm}^{-1}$, some of them are slightly over $400 \mathrm{~cm}^{-1}$. This means most of the shifts are caused by lattice displacements and possibly by Si and $\mathrm{Mg}$ displacements (compare Section 1).

In addition to results concerning the temperature we studied olivine samples with different crystal orientations as determined by a method described by Ishibashi et al. (2008) and Chopelas (1991). Comparing the temperature results from forsterite and the orientation from each of this olivine group it was proven that temperature depending shift of the Raman line position is linked with the orientation. The main axis $b$ in $\mathrm{Ol} 36$ as well as the $c$ axis of $\mathrm{Ol} 61$ and $\mathrm{Ol} 62$ exhibit one more shift $\left(339 \mathrm{~cm}^{-1} / 0136 ; 237 \mathrm{~cm}^{-1} / \mathrm{Ol} \mathrm{61}\right.$, Ol 62) than the $a$ axis. Known from Kuebler et al. (2006) for higher wavenumbers a correlation between component and positions of the peak wavenumbers has been shown.

In contrast to forsterite, where only the M2 translations and the $\nu_{2}\left(\mathrm{~B}_{1 \mathrm{~g}}\right)+\nu_{2}\left(\mathrm{~B}_{2 \mathrm{~g}}\right)$ modes (Chopelas, 1991) demonstrate significant temperature-dependent shifts, fayalite reacts more sensitive on low temperatures. In fayalite the significance of $\nu_{1}-\nu_{4}$ modes already starts at the Raman wavenumber of about $370 \mathrm{~cm}^{-1}$ depending on the symmetry (Chopelas, 1991). In the investigated fayalite there are three temperature dependings shifts at the Raman line positions at lower frequencies, which belong to the Raman active lattice modes. These are shifts at $155 \mathrm{~cm}^{-1}$ and $\sim 196 \mathrm{~cm}^{-1}$ which is a translational $\mathrm{SiO}_{4}$ mode, and a shift at $\sim 242 \mathrm{~cm}^{-1}$ belonging to a $\mathrm{SiO}_{4^{-}}$ libration mode. As for forsterite, these external lattice modes with a displacement of $\mathrm{SiO}_{4}$ as one unit are in this case Raman active. All other shifts are initiated by the $\mathrm{SiO}_{4}$ internal modes $\nu_{1}-\nu_{4}$ and have to be taken into account (Kuebler et al., 2006). Already the first Raman active mode with an internal shift shows considerable temperature behavior. At $\sim 385 \mathrm{~cm}^{-1}$ the $\nu_{2}$ symmetric bending mode is active for fayalite (Chopelas, 1991). This peak starts to increase in intensity and splits at around $150 \mathrm{~K}$ and ends at the lowest temperature in a resolved double peak at the wavenumbers $375 \mathrm{~cm}^{-1} / 389 \mathrm{~cm}^{-1}$. The next Raman active temperature depending modes are the asymmetric bending of $\mathrm{SiO}_{4}$ represented through the Raman line positions at $556 \mathrm{~cm}^{-1}$ and $\sim 669 \mathrm{~cm}^{-1}$ (Kuebler et al., 2006). Both peaks show a very large shift and were rather weak and broad at RT, but start to increase from $\sim 150 \mathrm{~K}$ down to $\sim 8 \mathrm{~K}$. Kuebler et al. (2006) and Chopelas (1991) assume that the Raman active stretching of $\mathrm{SiO}_{4}\left(\nu_{1}\right.$ and $\left.\nu_{3}\right)$ starts at around $700-950 \mathrm{~cm}^{-1}$. In this range another two changes in the Raman position lines were detected. The main peak at $818 \mathrm{~cm}^{-1}$ shows at RT a double peak of $\nu_{1}$ with the shoulder peak of $\nu_{3}$. With decreasing temperature starting again at $\sim 150 \mathrm{~K}$ the second shoulder peak forms one sharp peak at $\sim 8 \mathrm{~K}$ together with the main peak. Nearly the same behavior shows the $\nu_{3}$ active asymmetric stretching of $\mathrm{SiO}_{4}$ at a wavenumbers of $\sim 943 \mathrm{~cm}^{-1}$. This flat and very weak peak starts to increase in intensity at around $150 \mathrm{~K}$ and forms a large peak at $\sim 8$ K. Kolesov and Geiger (2004b), Ballett et al. (1989), and Robie et al. (1982) supposed an antiferromagnetic transition in fayalite at temperatures between $55 \mathrm{~K}$ and $65 \mathrm{~K}$. Furthermore Kolesov and Geiger (2004b) described the phenomena as a relationship between a magnetic transition and the internal vibrational modes. Acting in this assumption our observations prove the description of Kolesov and Geiger (2004b) of significant growth of various $\nu_{1}-\nu_{4}$ intramolecular modes, and, in addition, significant changes of the Raman position lines of these Raman active modes. Following our results the transition starts eventually smoothly already at around $150 \mathrm{~K}$.

\section{Conclusion}

The Raman spectroscopy results in combination with proper analytic methods allow conclusions significant for the application of Raman spectroscopy of bodies in our solar system. (1) Raman spectroscopy turned out to be an excellent non-destructive tool for a fast analysis of natural olivine including the determination of its composition and is therefore an outstanding instrument for space missions considering in-situ analysis at low temperatures. (2) All investigated olivines show shifts of positions of Raman active lines with decreasing temperature. Low-frequency lattice modes demonstrate significant shifts detectable with the used Raman spectrometer. Shift of most high-frequency modes cannot be resolved. Narrowing of the Raman lines with decreasing temperature allows to spectrally resolved closely lying vibrational modes that is crucial for analysis of complex mixtures of minerals, expected on planetary surface samples. (3) The temperature effect on the Raman active modes in fayalite is significantly higher than in forsterite, which probably has its origin in an antiferromagnetic transition coupled with a change of the vibrational modes. (4) Due to complex structure of the Raman spectra of olivines, an accurate determination of the line position requires multi-curve fit analyses, for instance multi-Gauss analysis used in this work.

The main aim of our study was to find out if Raman spectra are sensitive to low temperature at the Martian surface and, in addition, to other environmental conditions prevailing on other planetary objects. Our study proofs that there is no significant variation of the Raman spectra under Martian conditions, but they occur for lower temperatures. In addition, one has to be careful with the interpretation Raman spectra of olivine for temperatures lower than $\sim 150 \mathrm{~K}$. Fayalite reveals a considerable increase of intensity and shift of peak positions that are also known for forsterite, e.g. the peak at $968 \mathrm{~cm}^{-1}$ at $\sim 8 \mathrm{~K}$. Additionally, the instructions for determining olivine compositions according to Kübler et al. (2006) are only reduced applicable. The reason for this are the changes of the Raman peak positions at low temperatures.

\section{Acknowledgments}

The authors would like to thank U. Heitmann for sample preparation. This work is supported by a Grant 50 QX 0602 from the Deutsches Zentrum für Luft- und Raumfahrt to E.K. Jessberger. In addition, we would like to thank Prof. F. Langenhorst for providing some of the investigated samples.

\section{References}

Armstrong, J.T., 1991. Quantitative elemental analysis of individual microparticles with electron beam instruments. In: Heinrich, K.F.J., Newbury, D.E. (Eds.), Electron Probe Quantitation. Plenum Press, New York, pp. 261-315.

Ballett, O., Fuess, H., Wacker, K., Untersteller, E., Treutmann, W., Hellner, E., Hosoya, S. 1989. Magnetisation measurements of the synthetic olivine single crystal $\mathrm{A}_{2} \mathrm{SiO}_{4}$ with $\mathrm{A}=\mathrm{Mn}$, Fe or Co. J. Phys.: Condens. Matter 1, 4955-4970.

Birle, J.D., Gibbs, G.V., Moore, P.B., Smith, J.V., 1968. Crystal structures of natural olivines. Am. Mineral. 53, 807-824.

Chopelas, A., 1991. Single crystal Raman spectra of forsterite, fayalite, and monticellite. Am. Mineral. 76, 1101-1109.

Guyot, F., Boyer, H., Madon, M., Velde, B., Poirer, J.P., 1986. Comparison of the raman microprobe spectra of $(\mathrm{Mg}, \mathrm{Fe})_{2} \mathrm{SiO}_{4}$ and $\mathrm{Mg}_{2} \mathrm{GeO}_{4}$ with olivine and spinel structures. Phys. Chem. Miner. 13, 91-95.

Iishi, K., 1978. Lattice dynamics of forsterite. Am. Mineral. 63, 1198-1208.

Ishibashi, H., Arakawa, M., Ohi, S., Yamamoto, J., Miyake, A., Kagi, H., 2008. Relationship between Raman spectral pattern and crystallographic orientation of a rock-forming mineral: a case study of $\mathrm{Fo}_{89} \mathrm{Fa}_{11}$ olivine. J. Raman Spectrosc. 39, 1653-1659.

Jarosewich, E., Nelen, J.A., Norberg, J.A., 1980. Reference samples for electron microprobe analysis. Geostand. Newslett. 4, 43-47.

Kolesov, B.A., Geiger, C.A., 2004a. A Raman spectroscopic study of Fe-Mg olivines. Phys. Chem. Miner. 31, 155-161.

Kolesov, B.A., Geiger, C.A., 2004b. A temperature-dependent single-crystal Raman spectroscopic study of fayalite: evidence for phonon-magnetic excitation coupling. Phys. Chem. Miner. 31, 142-154. 
Kuebler, K., Jolliff, B.L., Wang, A., Haskin, L.A., 2006. Extracting olivine (Fo-Fa) composition from Raman spectral peak positions. Geochim. Cosmochim. Acta 70, 6201-6222.

Liu, L.-G., Mernagh, T.P., 1993. Raman spectra of forsterite and fayalite at high pressures and room temperatures. High Press. Res. 11, 241-256.

McMillan, P., 1985. Vibrational spectroscopy in mineral sciences. In: Kieffer, S.W. Navrotsky A. (Eds.). Microscopic to Macroscopic. Reviews of Mineralogy. vol. 14.

Motamedi, K., Colin, A., Hutchinson, I., Ingley, R., Davies, G., 2013. The effect of Martian conditions on the stoichiometry calculations of olivine (Fo-Fa) compositions using a combined Raman-Laser Induced Breakdown spectroscopy instrument. In: Proceedings of the 44th LPSC, \# 2264.

Mouri, T., Enami, M., 2008. Raman spectroscopic study of olivine-group minerals. J. Mineral. Petrol. Sci. 10, 100-104.

Paques-Ledent, M.T.H., Tarte, P., 1973. Vibrational studies of olivine-type compounds-I. The IR and Raman spectra of the isotopic species of $\mathrm{Mg}_{2} \mathrm{SiO}_{4}$. Spectrochim. Acta 29A, 1007-1016.

Price, G.D., Parker, S.C., Leslie, M., 1986. Lattice dynamics of forsterite. Mineral. Mag. 51, 157-170.

Rao, K.R., Chaplot, S.L., Choudhury, N., Ghose, S., Hastings, J.M., Corliss, L.M., Price, D.L., 1988. Lattice dynamics and inelastic neutron scattering from Forsterite, $\mathrm{Mg}_{2} \mathrm{SiO}_{4}$ : phonon dispersion relation, density of states and specific heat. Phys. Chem. Miner: $16,83-97$.

Robie, R.A., Finch, C.B., Hemingway, B.S., 1982. Heat capacity and entropy of fayalite $\left(\mathrm{Fe}_{2} \mathrm{SiO}_{4}\right)$ between 5.1 and $383 \mathrm{~K}$ : comparison of calorimetric and equilibrium values for the QFM buffer reaction. Am. Mineral. 67, 463-469.

Rull, F., Maurice, S., Dias, E., Tato, C., Pacros, A., and the RLS Team, 2011. The Raman Laser Spectrometer (RLS) on the ExoMars 2018 rover mission. In: Proceedings of the 42nd LPSC, \#2400.

Sharma, S.K., Cooney, T.F., 1990. Raman spectral study of $\mathrm{Fe}_{2} \mathrm{SiO}_{4}, \mathrm{Mg}_{2} \mathrm{SiO}_{4}$ $\mathrm{Mn}_{2} \mathrm{SiO}_{4}$, and $\mathrm{Ni}_{2} \mathrm{SiO}_{4}$ olivines between 15 and $293 \mathrm{~K}$. EOS 71, 525-526.

The ExoMars Programme 2016-2018. 〈http://exploration.esa.int/mars/46048-programme-overview $/\rangle$.

Vago, J.L., Coradini, M., EXOMARS, and EREP Teams, 2012. EXOMARS - Mars Exploration Programme. Mars Concepts 2012. Houston, TX.

Wang, S.Y., Sharma, S.K., Cooney, T.F., 1993. Micro-Raman and infrared spectral study of forsterite under high pressure. Am. Mineral. 78, 469-476.

William, Q., 1995. Infrared, Raman and optical spectroscopy of Earth materials Mineral Physics and Crystallography: A Handbook of Physical Constants, 291-301. 